\title{
Distant contact in the English-language discourse of the print media
}

\author{
Marina Levchenko ${ }^{1, *}$, Alena Sazhyna ${ }^{2}$, Nina Skitina $^{1}$ and Veronika Shabanova ${ }^{1}$ \\ ${ }^{1}$ Moscow State Region University, 10a, Radio Street, 105005, Moscow, Russia \\ ${ }^{2}$ Francisk Skorina Gomel State University, 104,Sovetskaya str, 246019, Gomel, Belarus
}

\begin{abstract}
Technological progress is making changes in all areas of our life, including interaction between people. Information is available thanks to various means, which make it possible to express an opinion in the socalled distant dialogue. In this sense, the discourse of the print media is not an exception, its participants come into contact and exchange opinions with a delay in time. The specifics of such a dialogue requires careful analysis in order to clarify the mechanisms of this kind of interaction, as well as the language means of contact in the press. Contact mechanisms and its language features are not studied well enough as readers have been able to send their responses to this or that article only recently. The developed methodology was tested on the material from the British newspaper "The Guardian". As a result, the authors have identified the external and internal dialogical structure in the discourse of the print media, as well as a set of language means of distant contact in the discourse. Moreover, understanding the distant dialogue nature helps to manage successful communication and can be used at practical classes in linguistics to develop students' skills in article and response writing and modeling dialogue situations.
\end{abstract}

\section{Introduction}

Since ancient times, the question of the laws of human communication has been exciting the minds of scientists in such fields as philosophy, psychology, sociology, cultural science, political science, etc., who consider communication as one of the attributive properties of matter, man's ability to learn the world and regulate his interaction with him, methods of communication, interpersonal perception and understanding, intergroup relations, etc. In turn, scientists in the field of linguistics deal with the problems of the emergence and development of language and speech as the most important means of human communication. Communication issues, which became the object of consideration in the works of such researchers as I. Herder, V. Humboldt, laid the foundations of linguistic science $[1,2]$. The theory of speech acts and pragmatic postulates of P. Grice were developed and are actively used in the analysis of all types of speech works [3]. Since the mid-20th century, the problems of discourse analysis have been actively developed. The text, which is "at the same time the form of existence of communication and its result" [4],

\footnotetext{
*Corresponding author: author@email.org
} 
and the discourse, which is a "coherent text together with extralinguistic - pragmatic, sociocultural, psychological and other factors; a text taken in the event aspect; speech, regarded as a purposeful, social action, as a component involved in the interaction of people and their mechanisms of consciousness (cognitive processes)" [4], occupy the central place in linguistic research as the main components of communication.

However, despite the fact that there are a large number of studies in the field of linguistic communication $[5,6,7,8,9]$, on the one hand, a number of questions are not fully covered, while other problems require new rethinking in connection with the changes that occur in the language under the influence of various extralinguistic factors. Our attention was attracted by the phenomenon of dialogization of the discourse of the print media, since the printed text, in addition to possessing the characteristics of the structural element of the discourse and performing its basic functions of transmitting information and influencing, becomes the structural element of a new type of dialogue - the dialogue between a journalist and a reader. Such a dialogue is conducted not only at the level of individual information fragments-replicas from the text of the article and readers' responses (the internal dialogical structure), but also replicas, which are the whole text of the article and response texts (the external dialogical structure) [10]. Moreover, such a dialogue is characterized by a delay in time caused by the distance between its participants, the presence of a mass abstract addressee, etc., which is due to the specific nature of this kind of dialogic interaction determines the relevance of the study.

As it is known, dialogue communication is impossible without contact, which has the following characteristics: the presence of at least two communicants; the emergence of an intention to start speech communication; the analysis of the partner and his predisposition to communication; creating an adequate environment for communication; the choice of a communication channel; the choice of the communication code; attracting the attention of the addressee; sending a request to set contact, etc. [11]. However, contact-setting in the discourse of the print media has certain differences from contact-setting in other types of discourse, due to the specificity of the structural-pragmatic organization of such dialogic communication. So, if we consider contact from the point of view of interaction between the sender of information and the addressee, then the pragmatic characterization and value of the transmitted information acquire leading importance. The nature of the relationship between the addresser and the addressee may also come to the fore, which, in turn, is determined by the role and intention of each of the participants in communication. In the discourse of the print media, the goal is to discuss and exchange information on any issue. At the same time, the author of the article can also pursue a number of secondary goals, such as encouraging readers to discuss different problems, informing, finding unanimity in opinion, etc. In turn, readers, by sending their responses to the article, also pursue various goals: expressing consent / disagreement with the opinion of the author of the article, the need to express their attitude to a particular problem, fulfilling the need for communication, etc. At the same time, it is undeniable that almost every goal assumes that the addressee has the intention to set contact with the addresser.

Despite the rather wide coverage of the mechanisms of dialogization of discourses of various types [4], the description of a set of contact-setting means in them, the question of implementing the contact-setting function in the discourse of the print media remains unexplored, since its dialogical nature has its own specifics, which, in our view is reflected in the choice of language means which mark the opening and setting of contact between the participants in the discourse we study. 


\section{Methods}

To solve all these problems, we propose to use several methods: the communicativepragmatic method, the comparative analysis method, the statistical method for processing empirical data. The practical analysis was carried out on the basis of articles and responses to them from the British newspaper "The Guardian", selected by the continuous sampling method. Thus, the use of the communicative-pragmatic method contributed to the study of the use of linguistic units by speakers in the process of communication together with their pragmatic properties, due to the communication situation, in order to achieve the result of contact and regulation of the communicative behavior of the participants in dialogue communication in the discourse of the print media. A set of language means has been identified that mark the contact between the addresser and the addressee during the dialogue.

Table 1. Language means of contact setting.

\begin{tabular}{|c|c|c|c|}
\hline \multirow[t]{7}{*}{$\begin{array}{l}\text { Inner- } \\
\text { text } \\
\text { level }\end{array}$} & \multirow{4}{*}{ 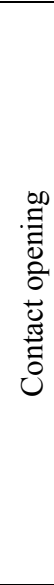 } & Personal pronouns & $\begin{array}{l}\text { If you want to know why the worst president in US } \\
\text { history currently stands a very good chance of } \\
\text { winning again, ... } \\
\ldots \text { and you get the same answer. } \\
\text { Before you change something, ... }\end{array}$ \\
\hline & & Imperative mood & $\begin{array}{l}\text {.. consider a few facts. } \\
\text { Ask quite different industries ... } \\
\text { Contrast that with Crossrail, ... }\end{array}$ \\
\hline & & Modal verbs/words & $\begin{array}{l}\ldots \text { you need to understand the problems. } \\
\text { Do you really have to ...? }\end{array}$ \\
\hline & & Questions & $\begin{array}{l}\text { Do you really have to suffer to "build character"? } \\
\text { But what of the fact that Facebook's algorithms } \\
\text { privilege the most hysterical, mendacious, loathsome } \\
\text { kind of political discourse? } \\
\text { Did they love the corruption-riven, dictator-prone } \\
\text { Nigeria? }\end{array}$ \\
\hline & \multirow{3}{*}{$\begin{array}{l}\ddot{\tilde{J}} \\
\stackrel{\tilde{\Xi}}{0}\end{array}$} & Thematic commonality & $\begin{array}{l}\text { What really helps Trump is Facebook (Article } \\
\text { "Trump's greatest ally in the coming election? } \\
\text { Facebook" John Harris). - Facebook wins whichever } \\
\text { way. Obama used Facebook, he owed his win to it. } \\
\text { Trump used Facebook, he owed his win to it. } \\
\text { Johnson used Facebook, ho owed his win to it. As } \\
\text { long as Facebook is seen as one of the principle } \\
\text { ways of getting elected, it's untouchable on any of its } \\
\text { dubious tax or revenue strategies (Reader } \\
\text { "leadballoon"). }\end{array}$ \\
\hline & & Agreement/disagreement & $\begin{array}{l}\text { What really helps Trump is Facebook (Article } \\
\text { "Trump's greatest ally in the coming election? } \\
\text { Facebook" John Harris). - The very idea that people } \\
\text { are able to do this, can fairly come to conclusion } \\
\text { different 'progressives' is simply impossible for them } \\
\text { to take it. No it must be 'evil right wing press and } \\
\text { stupid voters' (Reader "Guimard"). }\end{array}$ \\
\hline & & Answers to questions & $\begin{array}{l}\text { Question in the article: How did the soft left, seen as } \\
\text { the least reactive element of the compound, the } \\
\text { emollient middle child, manage to get three } \\
\text { candidates - Lisa Nandy, Emily Thornberry and Keir } \\
\text { Starmer - on to the list? } \\
\text { Answer in a reader's response: Soft left? No we } \\
\text { need hard hitting politics that counters all the lies of }\end{array}$ \\
\hline
\end{tabular}




\begin{tabular}{|c|c|c|}
\hline & & $\begin{array}{l}\text { the Conservatives and the hardship they have meted } \\
\text { out and the damage they have done to our } \\
\text { communities. }\end{array}$ \\
\hline \multirow[t]{2}{*}{$\begin{array}{l}\text { Whole- } \\
\text { text } \\
\text { level }\end{array}$} & Article (stimulus) & $\begin{array}{l}\text { "The EU won't fix its democratic deficit with } \\
\text { another top-down "conference"" } \\
\text { Alberto Alemanno }\end{array}$ \\
\hline & $\begin{array}{l}\text { Reader's Response } \\
\text { (reaction) }\end{array}$ & $\begin{array}{l}\text { JohnnySound (Reader 1), DrChed4r (Reader 2), } \\
\text { MikeDrew2101 (3) } \\
\text { etc. }\end{array}$ \\
\hline
\end{tabular}

Thanks to the use of the method of comparative analysis, it was possible to single out the specifics of the language of contact in the dialogical discourse of the print media in comparison with the natural dialogue, which is expressed in low usage or complete absence of language means of direct contact such as sentences with minimal syntactic complexity and the frequent use of interjections and their phraseological equivalents (well, eh, uh, etc.). The data were obtained due to the previous studies of linguistic signs of contact in direct dialogic communication.

Table 2. Language means of direct contact in the dialogue.

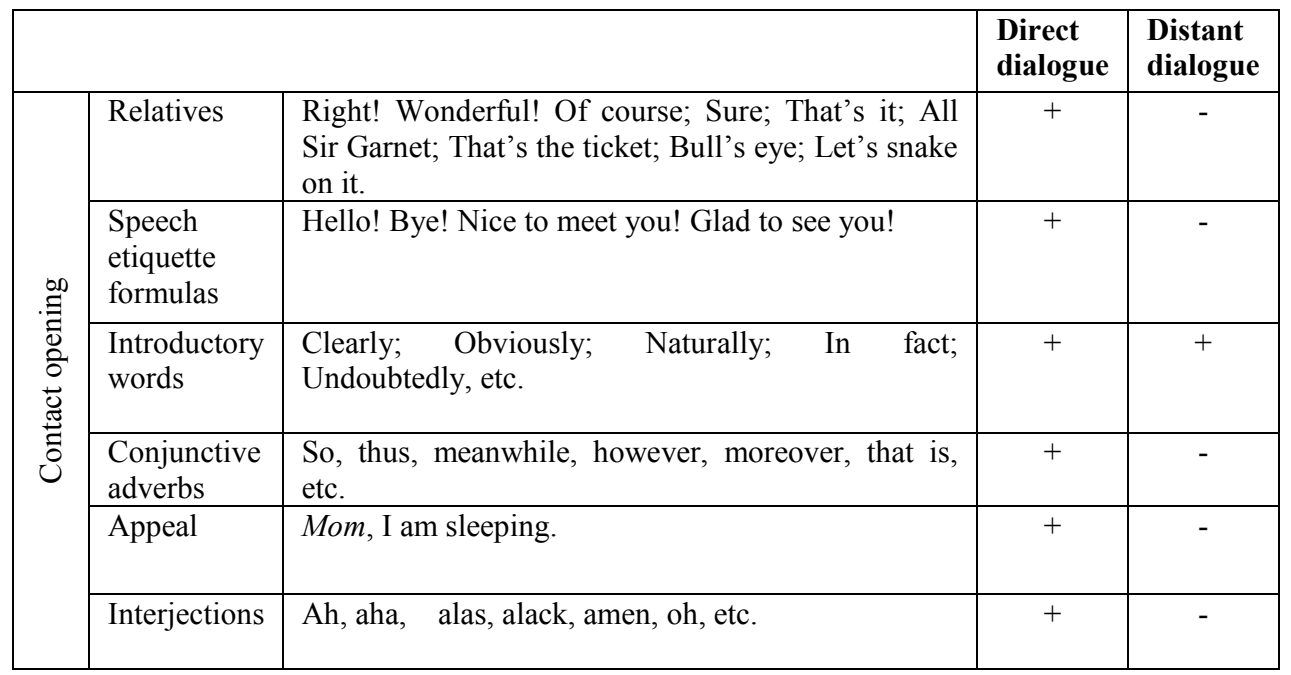

From Table 2 it is clearly seen that direct and distant dialogues coincide only in the use of contact-setting means of the language - in the use of introductory words.

The statistical method of processing empirical data, in turn, gave us the opportunity to establish the most common means of implementing the contact-setting function in the discourse of the print media.

Table 3. Rating of language means of contact realization.

\begin{tabular}{|c|c|c|c|c|}
\hline \multicolumn{5}{|c|}{ Contact opening } \\
\hline $\begin{array}{c}\text { Personal } \\
\text { pronouns }\end{array}$ & Imperative mood & $\begin{array}{c}\text { Modal } \\
\text { verbs/words }\end{array}$ & Questions & Others \\
\hline You & Open your eyes! & $\begin{array}{c}\text { You should } \\
\text { choose ... }\end{array}$ & $\begin{array}{c}\text { Doo you } \\
\text { know...? }\end{array}$ & Well, ... \\
\hline $32 \%$ & $18 \%$ & $10 \%$ & $37 \%$ & $3 \%$ \\
\hline
\end{tabular}

Table 3 presents two most widely used language means of contact setting - personal pronouns and questions, which were used in the contact opening function. The proof of 
contact setting lies in the thematic commonality in $99 \%$ cases, so it is possible to say the dialogue within the frame of the discourse of the print media took place.

\section{Results}

The study has showed that the dialogization of the English-language discourse of the print media takes place due to the fact that, first of all, there are conditions such as the presence of the addresser and the addressee, the intention and the goal of the dialogue between the communicants. But unlike the standard dialogue, which takes place in face-to-face communication, on the phone, etc. we are dealing with a specific dialogue, which is simultaneously conducted at the level of the whole texts (articles and responses to them) and individual remarks-statements, which are represented by fragments of texts of articles and responses. Special conditions for setting contact in the discourse of the print media, such as time delay caused by the distance between its participants, the mass addressee, the information transmission channel (the Internet and the print version of a newspaper) influence the choice of language means for implementing the contact-setting function in the discourse under study. So, unlike language means of setting contact in a standard dialogue (using proper names as an appeal (Hey, Mike!), greeting words (hello, hi), speech cliches (How's your life going on?), etc.) in most cases, in the model of dialogue under discussion, the main role in opening contact is given to the 2 nd person pronoun, which performs the appellative function to draw the reader's attention to the content of the article. It is noteworthy that in most cases, the pronoun you is combined with the use of modal verbs need, should, words with a modal meaning or the imperative in these statements.

Like in everyday dialogue, one of the leading roles in setting contact is played by interrogative statements, which, as a result of opening the contact, form intertextual question-answer complexes formed by the questions contained in the article and answers to the questions which are put in the responses of the recipients. Such interrogative statements are aimed at stimulating a response from readers, entering into a dialogue, and setting contact. In this case, we can introduce the term "distant contact", i.e. the one, carried out at a distance, without direct face-to-face contact.

Since in the model of dialogue under consideration, on the one hand, the article acts as a replica-stimulus, and the reaction is the reader's response, the main sign of contact in such a dialogue is the reader's response to the article. Another main sign of setting contact between participants in such a dialogue is the thematic commonality, the expression of agreement / disagreement with the author of the article, and the reader's answers to questions which are put by the author in the article.

Thus, the thematic commonality is proved by exact repetitions of the vocabulary from the article by the reader in his response (Article: What really helps Trump is Facebook. Response: Facebook wins whichever way). The thematic commonality can also be proved by thematic groups and semantic fields. So, the lexical units from the article formed thematic groups with lexical units from the responses of readers: the old school (in the article) - the whole bunch (in the responses); a mirror-Johnson, a "world queen", a celebrity, a clown (in the article) - a puppet in other hands, Pinochio (in the responses), etc. These units are combined on the basis of linguistic commonality, but according to a certain criterion, and the objects or concepts designated by them are expressed by different words.

A set of linguistic units, united by a common meaning and representing the subject, conceptual or functional similarity of the designated phenomena such as hospitals, a patient, medical emergency, the emergency team, a state of emergency, health system (in the article) - clinical circumstances, diagnosis and treatment, patient suffering, etc. (in the responses), belong to the semantic field and prove contact setting. 
If we look at Figure 1, we can see the distribution of language means of the thematic commonality in the discourse of the print media.

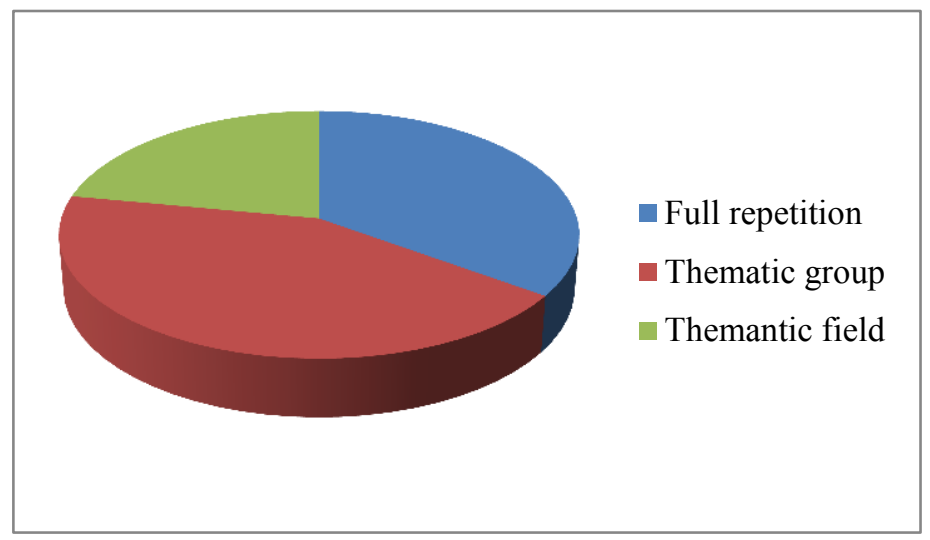

Fig. 1. Language means of the thematic commonality.

The expression of consent / disagreement of the reader with the author of the article, i.e. expressing a positive / negative response to a statement, suggestion, statement, etc., also receives language realization through the use of various language means: For those dying on A\&E trolleys, for those with cancer diagnoses caught too late and for the future of the NHS, it's time to stand up and fight back - it's time for us to strike (article). - I'm not sure it makes sense to strike. Either your strike doesn't actually harm the operations of A n E and is therefore ineffective or it does and results in patient suffering. I think the best way forward is to do what you are doing now. Those like me with long-lasting health conditions watch in horror as the Tories make a mess of the NHS (response 1). - I am totally with you and I hope your plan is taken up by the health unions (response 2). - Wait for all the negative responses to this doctor's article. He has my total sympathy for the circumstances in which he finds himself working (response 3 ), etc. The use of verbs, nouns and adjectives with the meaning of consent / disagreement proves the reaction to the opinion expressed by the author in the article, thereby indicating the setting of contact between the participants in the dialogue. It should also be emphasized that the expression of consent / disagreement is accompanied by the use of language units for the implementation of the thematic commonality as it is shown in Figure 2.

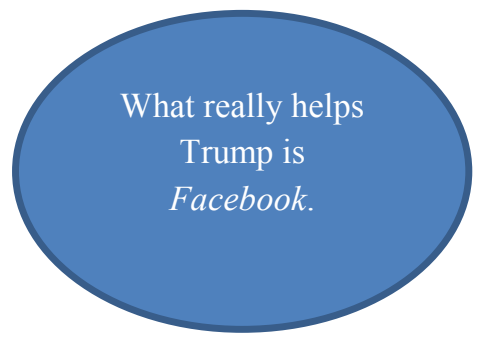

Article

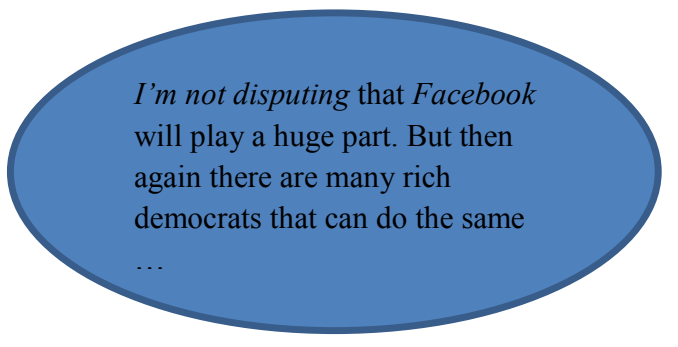

Response

Fig. 2. Language means of consent / disagreement and the thematic commonality.

Further investigation has allowed us to find the readers' answers to the questions which were put by the author of the article, which also proves the contact between two participants of the dialogue in the discourse of the print media (Next Friday, Britain officially leaves the EU but it's difficult to see who or what is being liberated. Perhaps an 
England without London? (article) - Still, this week fires the starting gun for rejoining the EU. Not for England without London, perhaps, but for the rest of us in some shape or form (response)).

Thus, the contact in the discourse of the print media is proved by the presence of language features in the dialogue between the addresser and the addressee of the studied discourse.

\section{Discussion}

To test the developed methodology of contact studies, the authors have investigated 30 articles from the British newspaper "The Guardian" with a total of 180 printed pages and responses to them with a total of 15,140 printed pages. The proposed methodology for identifying the main language markers of contact in the discourse of the print media can help identify signs of dialogue and contact in the study of the Internet discourse, political, judicial, pedagogical and other types of discourse, as well as in comparative studies of discourses in other languages.

The results can be used in courses of text linguistics, discourse analysis, theoretical grammar of the English language, communicative grammar, practice of oral speech and in the courses "The Discourse of the Print Media", "Language of the Media" in higher educational institutions.

Identified during the investigation, the language means of contact in the Englishlanguage discourse of the print media can be recommended for use in developing students' skills in writing a newspaper article and responses to it, as well as for modeling dialogue situations within the framework of the discipline "Practice of oral and written speech of the English language" on the topic "Mass Media".

\section{Conclusion}

The modern world cannot be imagined without the media, which perform not only the function of transmitting information, but also influence the opinion of the audience. As a result of this impact, communication participants are able to discuss and solve many issues on which the future of people depends. And in this communication process, the dialogue that arises under the influence of many factors in the press is of interest to researchers in terms of studying the mechanisms of opening and setting contact, without which it is impossible to imagine successful communication. Therefore, the proposed methodology of research and the identification of language markers that prove the successful implementation of the goal - informing and influencing - can become the basis for proving the dialogic nature of the studied discourse and continuing research in the field of pragmalinguistics. The combination of the communicative-pragmatic method, the method of comparative analysis and the statistical method of processing empirical data provided evidence for the results and can form the basis for further research. Due to the identified signs of the dialogue discourse of the print media and the identified set of contact-setting means, it is possible to develop possible communicative models of the distant dialogue, as well as to study the most effective means of realizing the impact in order to stimulate the response from the maximum number of addressees. The results obtained are also of interest for implementation in the educational process in higher education institutions as part of courses for students of linguistic specialties and future translators, as well as journalists. This study provides an opportunity to study the linguistic corpus of articles and readers' responses to them on the material of various languages in order to identify the most common linguistic units in the studied texts. 


\section{References}

1. J.G. Herder, Von der Natur und Wirkung der lyrischen Dichtkunst (Stuttgart und Tübingen, I.G. Cotta'scher Verlag, 1862)

2. V. Humboldt, Selected Works on Linguistics (Moscow, Progress, 1984)

3. G.P. Grice, New in Foreign Linguistics 16, 217 (1985)

4. N.D. Arutyunova, Logical analysis of the language: mono-, dia-, polylogue in different languages and cultures (Moscow, Indrik, 2010)

5. I.N. Borisova, Russian Conversational Dialogue: Structure and Dynamics (Moscow,Librocom, 2009)

6. V.N. Yartseva, Linguistic Encyclopedic Dictionary (Moscow, Soviet Encyclopedia, 1990)

7. L.G. Vikulova, E.G. Tareva, Dialogue of cultures. The culture of dialogue: man and new socio-humanitarian values (Moscow, NEOLITH, 2017)

8. L.R. Duskayeva, Dialogical nature of newspaper speech genres (St. Petersburg, SPbSU, 2012)

9. V.A. Maslova, Modern Trends in Linguistics (Moscow, Akademiya, 2008)

10. A.V. Sazhyna, Structural and Pragmatic Characteristics of the Polemic Discourse (Minsk, MSLU, 2007)

11. G.V. Karpuk, Vestnik MSLU 1, 35 (2010) 